\title{
Developing fire danger models using logistic regression analysis for mid-hills of Himachal Pradesh
}

\author{
DIVYA MEHTA, P.K. BAWEJA and R.K. AGGARWAL \\ Department of Environmental Science, College of Forestry, Dr. Y S Parmar University of Horticulture and Forestry Nauni, \\ Solan, 173 230, India. \\ Corresponding author: divya.mehta1726@gmail.com
}

\begin{abstract}
The present study intended to develop a climatic fire danger model for mid-hills zone of Himachal Pradesh using ten years weather data in relation with forest fire occurrence (2007-2016). Logistic regression technique was used to determine the relationship between fire occurrence and weather parameters viz., maximum temperature $\left({ }^{\circ} \mathrm{C}\right)$, relative humidity $(\%)$, and wind speed $\left(\mathrm{ms}^{-1}\right)$. The model was validated by calculating area under curve (AUC), coefficient of determination $\left(R^{2}\right)$ and root mean square Error (RMSE), with estimated values of $88.90 \%, 0.705$ and 0.247 , respectively. The fire danger model was verified with actual fire incidences in the study area during the year 2017. Wald's test was carried out to quantify impact climatic parameters on forest fire. Wald's test value was highest for maximum temperature (40.07) followed by relative humidity (1.15) and wind speed (0.75), respectively. In future such model can be utilized for prevention of forest fire hazards in the study area.
\end{abstract}

Key words: Fire danger model, fire occurrence, logistic regression model

As climate change has become a reality, the implications of global warming for changes in extreme weather and climate events are of major concern for agrarian as well as civic society. Forest fires are widespread and critical aspect of the earth system. A warmer and drier climate is expected to lead to more intense and frequent forest fire incidences. The earth had experienced 40 consecutive years (since 1977) that the annual temperature has been above the twentieth century average (Bal and Minhas, 2017). This might have influenced the chance of fire incidences across the globe including that of India. The annual global area burned due to forest fire ranges from 300 and 450 Mha (Van der Werf et al., 2006), which is comparable to the size of India. The Indian forests are vulnerable to forest fires depending on the type of vegetation and climate. The coniferous forest in the Himalayan region, which mainly consist of Abies species, Picea smithiana, Cedrus deodara, Pinus roxburghii and Pinus wallichiana are more prone to forest fires. The total forest area of Himachal Pradesh is 37, $033 \mathrm{~km}^{2}$ out of which $1,46,000$ ha is sensitive to fire (Bahuguna and Singh, 2002). Mid-hills zone of Himachal Pradesh is highly prone to forest fires during summer due to the presence of conifer species like pine due to shedding of highly inflammable chir pine needles (Shah and Sharma, 2015). This necessitated deriving fire danger model using logistic regression analysis based on climatic variables for mid-hills of Himachal Pradesh.
Several workers have developed and tested linear regression, logistic regressions, correlations, fuzzy logistic models and other techniques for forest fire risk modelling (Baweja 2014; Hamadeh et al., 2018). These models included few weather parameters. Therefore, to study all major weather parameters a wholesome approach was needed.

Weather parameters are critical aspects of fire activity. Cary et al. (2006) found that landscape fire models were generally more sensitive to variation in climate as compared to terrain complexity and fuel patterns. Prasad et al. (2008) and Vadrevu et al. (2010) found that mean annual temperature and average precipitation were among the variables that best explained fire occurrences. Average annual loss due to forest fire emissions in Himachal Pradesh was estimated to be Rs. 1.13 crores (Anonymous, 2016). Forest fires can lead to damage to vegetation cover, loss of natural regeneration, loss of wildlife habitat, change in micro-climate, loss of biodiversity, invasion of weeds, adverse effect on livelihood of people, loss of carbon sink, increase in greenhouse gases and also impact on air quality. Hence, there was need to develop a weather model for prediction of forest fire occurrences in the study area.

\section{MATERIALS AND METHODS}

Present study was carried out in mid-hills zone of Himachal Pradesh (Fig. 1) located between latitudes $30.32^{\circ}$ 


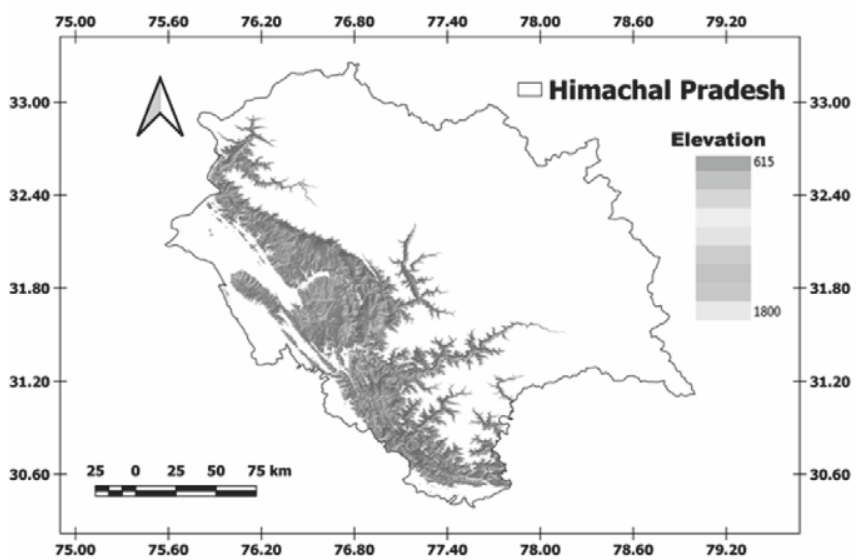

Fig. 1: Study area map

and $33.19^{\circ} \mathrm{N}$ and longitudes $75.58^{\circ}$ and $78.98^{\circ} \mathrm{E}$ at an altitude of 615 to $1800 \mathrm{~m}$ with a total spread of $11,743 \mathrm{ha}$. The area was comprised of pure and mixed stands of Pinus roxburghii, hence more susceptible to forest fires.

The weather data viz. maximum temperature, relative humidity and wind speed for the fire season (April, May and June) of 10 years (2007-2016) recorded at peak burning hours (1400-1500 hrs) of the day were collected from Agrometeorological Observatory of Department of Environmental Science, Dr. YS Parmar University of Horticulture and Forestry, Nauni, Solan. These weather parameters in relation to fire events had been analyzed in order to generate fire danger model. During the past 10 years, there were 31 fire days out of 910 days. The forest fire event was used as a binary variable represented by zeros and ones only, where zeros represent no fire and ones indicate fire occurrence during the particular day (Garcia et al., 1995). The data collected on forest fire incidences in the study area was obtained from Solan Forest Range, Himachal Pradesh.

\section{Logistic regression analysis}

Logistic regression was used as mathematical modeling technique to describe the relationship of several climatic variables to a dichotomous dependent variable viz. fire occurrence (Vasconcelos et al., 2001). The logistic regression model was obtained using stepwise regression on the data sets.
In the analysis Wald's test was also used. The Wald's test determined the significance of an individual climatic variable in the presence of the other variables included in the model. The validation of logistic models entails the quantification of their predictive ability and an assessment of the possibilities of extrapolation to independent data sets. Analysis was carried out using Microsoft Excel 2010.

\section{RESULTS AND DISCUSSION}

Fig. 2 demonstrats the relation between fire occurrence and weather parameters. $\mathrm{X}$-axis represents the total number of days during the period 2007-16, Y-axis represents the magnitude of weather parameters and fire occurrence during a particular day.

\section{Maximum temperature $\left({ }^{0} \mathrm{C}\right)$}

Forest fire accidents had occurred when the maximum temperature was at peak (Fig. 2a). This may be due to enhancement evaporation rate of fuel moisture, hence facilitating fire ignition. Same results was also demonstrated by previous studies (Hamadeh et al., 2017) for similar ecogeographical area, where maximum temperature was significant in fire ignition.

\section{Relative humidity (\%)}

The effect of relative humidity on fire occurrence is shown in Fig. 2b. Relative humidity revealed strong negative correlation with fire occurrences in the study area. When the relative humidity was low, the moisture in the fuel was readily evaporated as it rises to the surface of the fuel. When the humidity was high, it was harder for the moisture to evaporate into the air. The fire accidents occurred when relative humidity was less than $60 \%$. Results were in support of findings of Sosebee et al. (2007) and Eric et al. (2009), which demonstrated that most of the fire occurred only when the relative humidity was less than $55 \%$.

\section{Wind speed $\left(m s^{-1}\right)$}

Fire behavior was strongly affected by wind speed (Fig. 2c). Wind was an important factor because it provided fresh

Table 1: Details of variables used for development of Fire Danger Model

\begin{tabular}{lrrrr}
\hline Variables & Coefficient & Std. Error & Wald & $\mathrm{p}$-value \\
\hline Maximum temperature $\left({ }^{\circ} \mathrm{C}\right)$ & 0.562 & 0.088 & 40.073 & $<0.0001$ \\
Relative humidity $(\%)$ & -0.019 & 0.017 & 1.147 & 0.283 \\
Wind speed $\left(\mathrm{ms}^{-1}\right)$ & 0.031 & 0.036 & 0.751 & 0.386 \\
Constant & -21.126 & 3.252 & 42.187 & $<0.0001$ \\
\hline
\end{tabular}


(a)

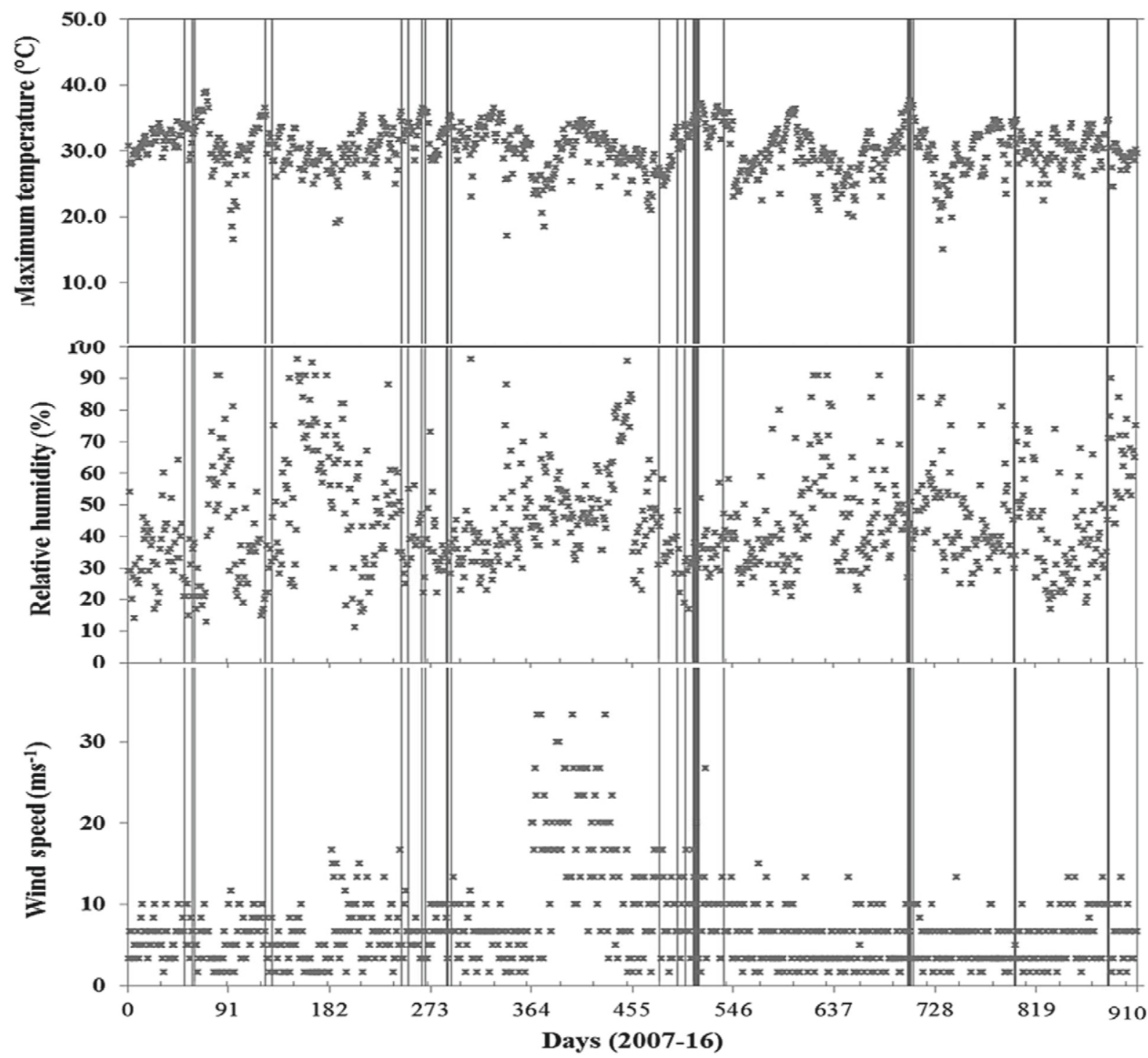

(b)

(c)

Fig. 2: Weather parameters in relation with fire occurrence over the fire season of 10 years (2007-2016)

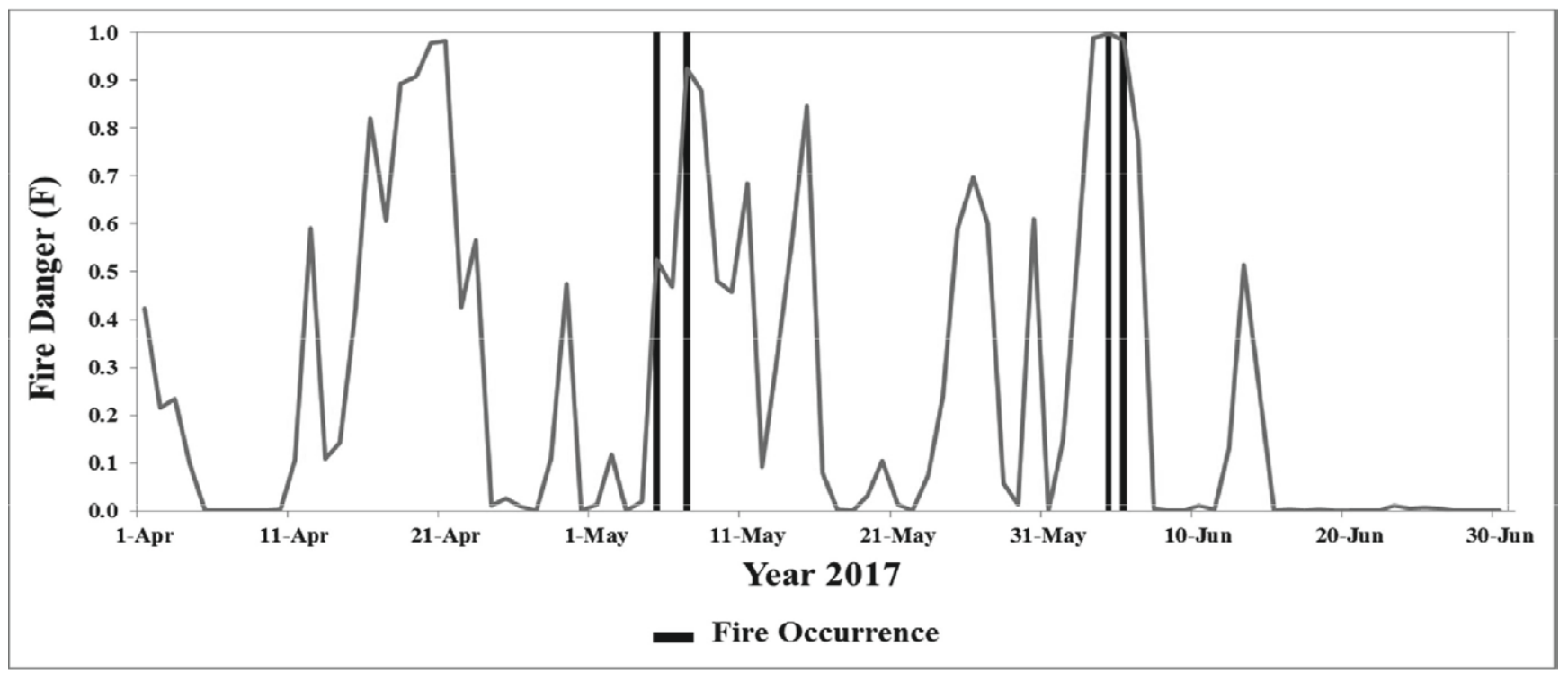

Fig. 3: Validation of Fire Danger Model for the fire season of 2017 
oxygen and spread flames to new fuel source. Pourghasemi et al. (2016) showed that fire accidents were strongly affected by wind speed.

\section{Fire danger model}

Fire danger model that fits the study site was derived through a logistic regression analysis. The value of $\mathrm{R}^{2}$ for the logistic regression model at $5 \%$ degree of freedom was 0.705 and RMSE was 0.247 . Higher value of $\mathrm{R}^{2}$ and lower values of RMSE indicated better fit. The Wald's test revealed the significance of individual climatic variable in the presence of the other variables included in the model. Wald's test value was highest for maximum temperature (40.07) followed by relative humidity (1.147) and wind speed (0.75), respectively (Table 1).

$$
\log \left(\frac{\mathrm{F}}{1-\mathrm{F}}\right)=0.562(\mathrm{~T})-0.019(\mathrm{RH})+0.031(\mathrm{WS})-17.326
$$

$$
\begin{array}{cll}
\text { Where; } & \\
\mathrm{F} & = & \text { Fire danger } \\
\mathrm{T} & = & \text { Maximum temperature }\left({ }^{\circ} \mathrm{C}\right) \\
\mathrm{RH} & = & \text { Relative humidity }(\%) \\
\mathrm{WS} & = & \text { Wind speed }\left(\mathrm{m} \mathrm{s}^{-1}\right)
\end{array}
$$

\section{Validation offire danger model}

To determine the accuracy of the logistic model, the ROC curve (Pourghasemi et al., 2016) was used. The ROC curve was developed by using true positive rate and false positive. It represented the trade-off between the two rates. In the ROC method, the area under the curve (AUC) values was used to evaluate the model accuracy. The quantitative and qualitative relationship between AUC and prediction accuracy was classified as follows: $0.90-1.00$, excellent; $0.80-0.90$, very good; 0.70-0.80, good; 0.60-0.70, average; and 0.50-0.60, poor (Pourghasemi et al., 2016). The calculated AUC for the model was $88.90 \%$ i.e. very good.

Certain other measures viz., accuracy, specificity, sensitivity and precision were used for testing and evaluating Fire Danger Model. The computed accuracy, specificity, sensitivity and precision for Fire Danger Model were 96.20\%, $90.27 \%, 94.66 \%, 89.94 \%$ and $98.12 \%$ respectively. The model was verified using fire season data of the year 2017 (Fig. 3). The model was able to predict all fire occurrences and hence can be used for controlling forest fire incidences in the present study area.

\section{CONCLUSION}

The present investigation identified forest fire risk as a function of climatic attributes. Three parameters (maximum temperature, relative humidity and precipitation) are the most influential ones that induce fire in the forestland. The fire danger model (AUC=88.90\%) using logistic regression analysis, was found to be the best model for fire prediction in the study area.

\section{ACKNOWLEDGMENT}

The assistance provided by Dr S.K. Bhardwaj, Professor and Head, Department of Environmental Science and Dr I.K. Thakur, Principal Scientist, Department of Tree Improvement and Genetic Resources, Dr Y.S. Parmar University of Horticulture and Forestry, Nauni, HP-India in the present study is highly acknowledged. I would also acknowledge Dr Y.S. Parmar University of Horticulture and Forestry, Nauni, HP-India for providing merit scholarship during my postgraduation in Forestry with specialization in Environmental Management.

\section{REFERENCES}

Anonymous. (2016). "Forest fires and its effect on environment, forests, bio-diversity and wildlife and remedial/preventive measures". Department-related parliamentary standing committee on Science \& Technology, Environment \& Forests. Pp 1-35.

Bahuguna, V.K., and Singh, S. (2002). Fire situation in India. Int. Forest Fire News, 26: 23-27.

Bal, S.K. and Minhas, P.S. (2017). Atmospheric Stressors: Challenges and Coping Strategies. In: "Abiotic Stress Management for Resilient Agriculture”. (Eds. P.S. Minhas et al.). pp. 9-50, Springer Nature Singapore Pte. Ltd.

Baweja, P.K. (2014). "Meteorology Based Prediction Models for Management of Forest Fires in Shivalik Hills, India". M Sc Thesis. Shoolini University of Biotechnology and Management Sciences Nauni, Solan (H.P.) India. 69p.

Cary, G.J., Keane, R.E., Gardner, R.H., Lavorel, S., Flannigan, M.D., Davies, I.D., Li, C., Lenihan, J.M., Rupp, T.S. and Mouillot, F. (2006).Comparison of the sensitivity of landscape-fire-succession models to variation in terrain, fuel pattern, climate and weather. Land. Ecol., 21(1): 121-137. 
Eric, E.K., Becky, L.E. and Carl, N.S. (2009). "Ecological effects of prescribed fire season: a literature review and synthesis for managers". USDA Forest Service, Pacific Southwest Research Station, United States. 224p.

Garcia, C.V., Woodard, P.M., Titus, S.J., Adamowicz, W.L. and Lee, B.S. (1995).A logit model for predicting the daily occurrence of human caused forest-fires. Int. J. Wild. Fire, 5(2): 101-111.

Hamadeh, N., Ali, K., Daya, B. and Chauvet, P. (2017).Using correlative data analysis to develop weather index that estimates the risk of forest fires in Lebanon \& Mediterranean: Assessment versus prevalent meteorological indices. Cas. Stu. Fir. Saf., 7: 8-22.

Pourghasemi, H.R., Beheshtirad, M. and Pradhan, B. (2016). A comparative assessment of prediction capabilities of modified analytical hierarchy process (M-AHP) and Mamdani fuzzy logic models using Netcad-GIS for forest fire susceptibility mapping. Geo. Nat. Haz. Ris., $7(2): 861-885$.

Prasad, V.K., Badarinath, K.V.S. and Eaturu, A. (2008).Biophysical and anthropogenic controls of forest fires in the Deccan Plateau, India. J. Env. Manage., 86(1): 1-13.

Shah, S. and Sharma, D.P. (2015). Land use change detection in Solan Forest Division, Himachal Pradesh, India. For. Ecol., 2(1):26-38.

Sosebee, R.E., Wester, D.B., Britton, C.D., McArthur, A.D. and Kitchen, S.D. (2007). "Shrubland Dynamics Fire and Water". USDA, Forest Service, Rocky Mountain Research Station, United States. 173p.

Vadrevu, K.P., Eaturu, A., and Badrinath, K.V.S. (2010).Fire Risk Evaluation using multicritiria analysis- A case study. Env. Monitor. Assess., 166(4): 223-239.

Van der Werf, G.R., Randerson, J.T., Giglio, L., Collatz, G.J., Kasibhatla, P.S. and Arellano, Jr A.F. (2006). Inter annual variability in global biomass burning emissions from 1997 to 2004. Atm. Chem. Phys., 6(11): 3423-3424

Vasconcelos, M.P., Silva, S., Tome, M., Alvim, M. and Pereira, J.C. (2001). Spatial prediction of fire ignition probabilities: comparing logistic regression and neural networks. Photo. Engi. Remote Sens., 67(1): 73-81. 